\title{
The Role of Staking and Pruning Methods on Yield and Profitability of Tomato (Solanum lycopersicum L.) Production in the Guinea Savanna Zone of Ghana
}

\author{
S. Lamptey (iD) and E. Koomson \\ Department of Agronomy, Faculty of Agriculture, University for Development Studies, P. O. Box TL 1882, Tamale, Ghana \\ Correspondence should be addressed to S. Lamptey; naalamp2009@yahoo.com
}

Received 19 February 2021; Revised 14 July 2021; Accepted 2 September 2021; Published 18 September 2021

Academic Editor: Amelia Salimonti

Copyright ( $\odot 2021$ S. Lamptey and E. Koomson. This is an open access article distributed under the Creative Commons Attribution License, which permits unrestricted use, distribution, and reproduction in any medium, provided the original work is properly cited.

\begin{abstract}
Tomato is one of the most widely consumed and produced vegetables in Ghana. The low yield of tomatoes in Ghana has resulted in huge importation of the produce from neighboring countries. Good agronomic practices are among the key strategies involved in increasing the yield of horticultural produce. This study seeks to evaluate the response of staking and pruning on tomato fruit yield, quality, and cost of production. To achieve this, a field experiment was conducted to investigate the effect of staking and pruning methods on fruit yield and profitability of tomato (Solanum lycopersicum L.) produced in the northern region of Ghana. Treatments were applied in a randomized complete block design with three replications. Treatments were no pruning + no staking (control), single pole staking (SPS), wire trellis (WT), one-stem pruning (1SP), one-stem pruning + single pole staking (1SP + SPS), one-stem pruning + wire trellis (1SP + WT), two-stem pruning (2SP), two-stem pruning + single pole staking (2SP + SPS), and two-stem pruning + wire trellis $(2 \mathrm{SP}+\mathrm{WT})$. Results showed that 2SP + WT increased fruit diameter, fruit length, and marketable fruit weight by $52 \%, 32 \%$, and $69 \%$, respectively, compared to the control. The maximum number and weight of marketable fruits obtained from 2SP + WT increased total fruit yield by $76 \%$ compared to the control. In all, the performance of the treatments in terms of yield was in the following order: $2 \mathrm{SP}+\mathrm{WT}>1 \mathrm{SP}+\mathrm{WT}>\mathrm{SPS}>\mathrm{WT}>2 \mathrm{SP}+\mathrm{SPS}>1 \mathrm{SP}>2 \mathrm{SP}>$ control. Though $2 \mathrm{SP}+\mathrm{WT}$ increased production cost by $42 \%$, it greatly increased yield by $69 \%$ which resulted in $83 \%$ net profit compared to the control. Thus, 2SP + WT could be tested on-farm for possible adoption to increase tomato yield, quality, and profit.
\end{abstract}

\section{Introduction}

Tomato is an important component of every Ghanaian meal, and its cultivation contributes significantly to livelihood improvement. Schippers [1] asserts that tomato is the most important vegetable in Ghana, compared to all the other vegetables. The total consumption of fresh tomato in 2016/ 2017 was 240,000 tons per annum [2]. However, domestic production has not kept up with demand [3]. The tomato sector is unable to attain its potential productivity as compared to other countries [4]. The average tomato yield in Ghana is $7.5 \mathrm{t} /$ ha which is far less than the potential yield of 20 tons per hectare [5]. Ghana imports close to 100,000 tons or one-quarter of its domestic supply from a neighboring country (Burkina Faso) to meet the domestic demand [6, 7].
This has resulted in large sums of money spent annually on the importation of the vegetable crop. For example, 7,000 tons was imported annually between 2010 and 2016, mostly originating from Burkina Faso [3, 8]. Major contributing factor to the low tomato yield in Ghana is the use of traditional methods of farming or low adoption of improved husbandry practices (such as sustainable staking and pruning).

It is asserted that improved management practices such as staking and pruning could yield over 32.5-46.0 $\mathrm{t} / \mathrm{ha}$ in the forest zones of Ghana [9]. Staking is a means of providing supports to ensure clean and unblemished fruits by keeping fruits off the ground, thereby increasing marketable yield [6]. Akoroda [10] and Amina [11] suggested staking as an appropriate method to effectively expose leaves to sunlight for 
efficient photosynthetic activities and improved yield of crops. Pruning and staking indeterminate tomato plants can result in early fruits maturity and larger fruits. The most common method of staking among small holder farmers in Ghana is the single-pole staking where each crop is supported with stake (wood). This has resulted in scarcity of stakes [12], especially in Guinea savanna. Besides, this method is labor intensive and contributes greatly to deforestation resulting in an unsustainable production system. In pruning, there is the selective removal of side shoots or stem to limit plant growth and to divert nutrients to flower clusters on the remaining shoot or stem. According to Franco et al. [13], appropriate pruning method is relevant to maintain a balance in the relationship's source/sink and the carbon/nitrogen $(\mathrm{C} / \mathrm{N})$ ratio. Alam et al. [14] recorded increased marketable yield/area by pruning indeterminate tomato plants to two-stem rather than one-stem. Alternative staking technique that would reduce the quantity of stakes (wood) used without compromising on yields would address the problem of scarcity of stakes and deforestation associated with tomato production in Ghana. The objective of the study was to evaluate staking and pruning options to suggest alternatives for sustainable tomato production without compromising on yield and profitability. This is to address the problem of scarcity of stakes and deforestation associated with tomato production in Ghana.

\section{Materials and Methods}

2.1. Study Area and Experimental Design. The field study was conducted at the University for Development Studies (UDS) experimental fields, Nyankpala campus, from June to October 2019 under rain fed. Nyankpala is located on latitude $009^{\circ} 25^{\prime} 41^{\prime \prime} \mathrm{N}$, longitude $000^{\circ} 58^{\prime} 42^{\prime \prime} \mathrm{W}$, and altitude $183 \mathrm{~m}$ above sea level (SARI, 2007). The experiment was laid out in a randomized complete block design (RCBD) with nine treatments and three replications. There were a total of twenty-seven (27) experimental plots. The plot size for each experimental unit was $4 \mathrm{~m} \times 3 \mathrm{~m}$ with spacing of $1 \mathrm{~m}$ between plots and $2 \mathrm{~m}$ between blocks. A total field size of $33 \mathrm{~m} \times 13 \mathrm{~m}$ was demarcated for the experiment.

2.2. Nursing and Transplanting of Seedlings. A nursery trough measuring $10 \mathrm{~m} \times 1.3 \mathrm{~m}$ was prepared and filled with sandy loam soil mixed with biochar for nursing the seeds. Pectomech tomato seeds were thinly sown in drills on the nursery trough on $8^{\text {th }}$ July 2019. Nursed seeds were mulched with dry grass and watered twice a day at 3 days interval until germination. Ridges of $75 \mathrm{~cm}$ apart were prepared prior to transplanting with each plot having 4 ridges. Seedlings were transplanted four weeks after germination at a height of $15 \mathrm{~cm}$ with about 5-6 leaves. Transplanting was done late in the afternoon to prevent transplanting shock. Seedlings were planted at a spacing of $40 \mathrm{~cm}$ within rows and $75 \mathrm{~cm}$ between rows, with each ridge accommodating 10 seedlings. A total of 40 seedlings were planted on each plot. With the trellis, wires were run from one end pole to another and back again at different heights after transplanting. When the plant reached about $25 \mathrm{~cm}$ in height, the stem of the tomato was loosely tied to the wires for support.

With the single-stem staking, wooden stake of about $60-80 \mathrm{~cm}$ was inserted about $20 \mathrm{~cm}$ into the soil, just outside the diameter of the tomato seedling after transplanting. When the plant reached about $25 \mathrm{~cm}$ in height, the stem of the tomato was loosely tied to the supporting stake. Pruning started four weeks after transplanting (WAT) and continued to twelve weeks. All the suckers were removed to one below the first flower cluster to get one stem per plant or two stems per plant.

2.3. Data Collection. Data on yield parameters were taken five weeks after transplanting and at harvest. Five plants were selected from the two middle ridges from each treatment for the measurement of yield data, and their averages were computed. The yield parameters determined were as follows.

2.3.1. Number of Marketable and Nonmarketable Fruits. Marketable fruits were fruits of good quality in firmness with no blemish. Mature and ripped, unrotten and sizable (without blemish) tomato fruits were harvested from the five randomly selected plants from the two middle rows. Harvested fruits were counted and averaged to represent number of fruits per plant. Nonmarketable fruits were further sorted out into the following components:

(a) Sun-scalded, deformed, unevenly ripped, and whitish areas appearing on the exposed surface

(b) Fruits diseased or eaten by rodents

(c) Fruits eaten by birds, mainly full-ripe tomatoes

2.3.2. Fruit Diameter and Length. Three ripped fruits were randomly selected from the harvested fruits per the five tagged plants. With the aid of a caliper, the three fruits diameter was measured, and their means were calculated in $\mathrm{mm}$ at 9 weeks after transplanting. With the aid of a meter rule in $\mathrm{cm}$, the three fruits lengths were measured, and their means were determined at 9 weeks after transplanting.

2.3.3. Marketable Fruits Weight. Matured, ripped, unrotten, and sizable (without blemish) tomato fruits harvested from the five tagged plants were weighed and averaged at 8,9 , and 10 weeks after transplanting (WAT) to determine the weight of marketable fruits per plant at 8, 9, and $10 \mathrm{WAT}$. The mean weight in kilograms per hectare was extrapolated.

2.3.4. Total Fruits Yield. Tomato fruits were harvested 6 times on weekly basis per plot by hand picking and weighed. Fruit yield was determined by summing up all the weight of the six times harvest which includes marketable and nonmarketable fruits and measured in $\mathrm{Kg} /$ plot and later converted to $\mathrm{Kg} / \mathrm{ha}$. 
2.3.5. Economic Analysis. Production cost was calculated for each treatment by estimating the gross returns (total returns after production), net returns (gross return minus cost of production), and benefit cost ratio (net return divided by the production costs). Price of input and the market price of produce were used in calculating production cost, returns, and benefit:cost ratio.

2.4. Data Analysis. Data on all parameters, except economic analysis, were subjected to ANOVA using GenStat statistical package (GenStat, 20TH Edition). The means were separated using LSD (0.05).

\section{Results}

3.1. Fruit Length and Diameter. The result indicates that there was a significant $(p<0.002)$ difference among treatments on the fruit length at 9 WAT. Single pole staking (SPS), wire trellising (WT), one-stem pruning plus wire trellising $(1 \mathrm{SP}+\mathrm{WT})$, and two-stem pruning plus single pole staking $(2 \mathrm{SP}+\mathrm{SPS})$ showed no difference in fruit length, likewise one-stem pruning plus single pole staking and twostem pruning plus wire trellising. However, 2SP + WT had the highest $(5.1 \mathrm{~cm})$ fruit length compared to the control $(2.2 \mathrm{~cm})$ at 9 WAT (Figure 1$)$.

There was a difference $(p<0.049)$ in fruit diameter between $2 \mathrm{SP}+\mathrm{WT}(4.64 \mathrm{~cm})$ and the control $(2.21 \mathrm{~cm})$ at 9 WAT (Figure 2). However, there was no difference between single pole staking (SPS), wire trellising (WT), one-stem pruning plus single pole staking $(1 \mathrm{SP}+\mathrm{SPS})$, one-stem pruning plus wire trellising $(1 \mathrm{SP}+\mathrm{WT})$, one-stem pruning (1SP), two-stem pruning (2SP), and two-stem pruning plus single pole staking $(2 \mathrm{SP}+\mathrm{SPS})$.

3.2. Marketable Fruits Weight and Number. At 8,9 , and 10 WAT, there were significant differences $(p<0.001$, $p<0.001$, and $p<0.0019$, respectively) among treatments on the weight of marketable fruits. Plots treated with $2 \mathrm{SP}+\mathrm{WT}$ recorded the highest $(369 \mathrm{Kg} / \mathrm{ha})$ weight of marketable fruits compared with the control giving the least weight $(65 \mathrm{~kg} / \mathrm{ha})$ of marketable fruits at $8 \mathrm{WAT}$. $2 \mathrm{SP}+\mathrm{WT}$, $1 \mathrm{SP}+\mathrm{WT}$, and 2SP + SPS increased marketable fruit weight by $82 \%, 71 \%$, and $60 \%$, respectively, compared to the control at 8 WAT. A similar trend was observed in 9 and $10 \mathrm{WAT}$ (Table 1).

There was a significant $(p<0.001)$ difference among treatments on the number of marketable fruits at harvest with $2 \mathrm{SP}+\mathrm{WT}$ recording the highest $(11449.6 \mathrm{~kg} / \mathrm{ha})$ and $2 \mathrm{SP}+\mathrm{SPS}$, the next greatest $(7866.3 \mathrm{~kg} / \mathrm{ha})$. This resulted to $70 \%$ and $57 \%$ increase in number of marketable fruits by $2 \mathrm{SP}+\mathrm{WT}$ and $2 \mathrm{SP}+\mathrm{SPS}$, respectively, compared to the control (Figure 3 ).

3.3. Number of Nonmarketable Fruits. The analysis revealed that there was a significant $(p<0.001)$ difference among treatments on the number of nonmarketable fruits of tomato at harvest. Two-stem pruning plus wire trellising
$(2 \mathrm{SP}+\mathrm{WT})$ plots recorded the least number of nonmarketable fruits of $2089 \mathrm{~kg} / \mathrm{ha}$, while the control had the highest number of nonmarketable fruits of $7478 \mathrm{~kg} / \mathrm{ha}$ at harvest (Figure 4).

3.4. Total Fruit Yield. The analysis of variance indicates that there was a difference $(p<0.001)$ among treatments on total fruits yield. There was no difference between one-stem pruning (1SP), one-stem pruning plus single pole staking $(1 \mathrm{SP}+\mathrm{SPS})$, and two-stem pruning (2SP). There were significant differences between two-stem pruning plus wire trellising $(2 \mathrm{SP}+\mathrm{WT})$, two-stem pruning plus single-pole staking $(2 \mathrm{SP}+\mathrm{SPS})$, and no pruning no staking. Two-stem pruning plus wire trellising $(2 \mathrm{SP}+\mathrm{WT})$ increased total fruits yield by $75 \%$ compared to control (Figure 5).

3.5. Cost and Return Analysis. Cost analysis showed that 2SP + WT incurred the highest ( $\$ 411 / \mathrm{ha})$ cost of production, whereas the control incurred the lowest of $\$ 175 /$ ha (Table 2).

In the case of net return and benefit cost ratio (BCR), it was observed that $2 \mathrm{SP}+\mathrm{WT}$ recorded the highest $(\$ 598 / \mathrm{ha})$ net return as well as the maximum benefit cost ratio (1.46), whereas the control recorded the minimum net return $(\$ 63 /$ ha) and BCR (0.36).

\section{Discussion}

Staking and pruning methods greatly affected fruit diameter and length with the highest fruit diameter and length recorded in $2 \mathrm{SP}+\mathrm{WT}$. Staking with wire trellis might have allowed better aeration and exposure of the foliage, thereby, enhancing photosynthetic activities which might be responsible for larger fruit size. Hesamil et al. [15] reported increased fruit size of tomato because lateral branches were removed. The result obtained by staking tomatoes is in agreement with Kumar et al. [16] who reported higher fruit diameter in staked tomato.

The improved fruit diameter and length in $2 \mathrm{SP}+\mathrm{WT}$ resulted in $82 \%, 66 \%$, and $65 \%$ increase in marketable fruit weight in 8,9 , and $10 \mathrm{WAT}$, respectively, compared to control. 1SP + WT and 2SP + SPS also increased marketable fruit weight by $71 \%$ and $60 \%$, respectively, compared to the control at 8 WAT. Staking increases fruit yield, reduces the proportion of nonmarketable fruit, and enhances the production of high-quality fruits [17]. Ramirez et al. [18] reported that two or three stem pruning produced the best quality fruits. The result of this study is in agreement with [19] who reported that removal of lateral branches resulted in increasing fruit weight of tomato plants. The pruning and staking prevented tomato fruits from coming into contact with wet soil [20] and, therefore, reduced the number of nonmarketable yield due to fruit rot [21]. This resulted in increased fruit size thereby increasing weight and number of marketable yield of tomatoes. Kumar et al. [16] reported an increase in fruit weight of tomato by staking. Salinas et al. [22] reported higher good quality fruit in pruned tomatoes compared to no pruning. 


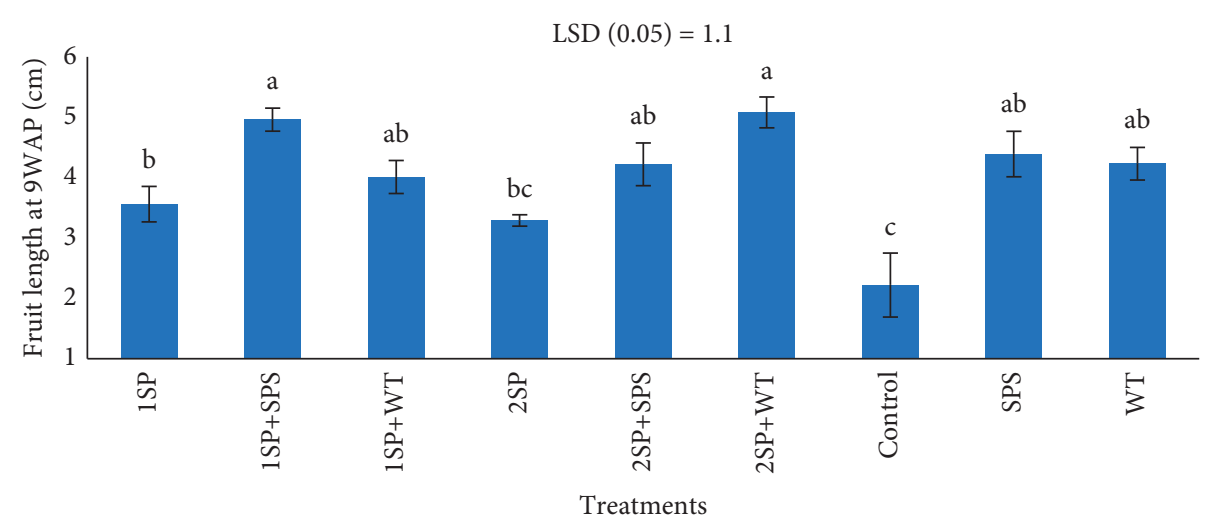

FIGURE 1: Effect of pruning and staking on fruit length. Bars with different letters denote significance at $p<0.05$. Error bars denote the standard error of means. Means comparison was conducted using the least significant difference $(p<0.05)$.

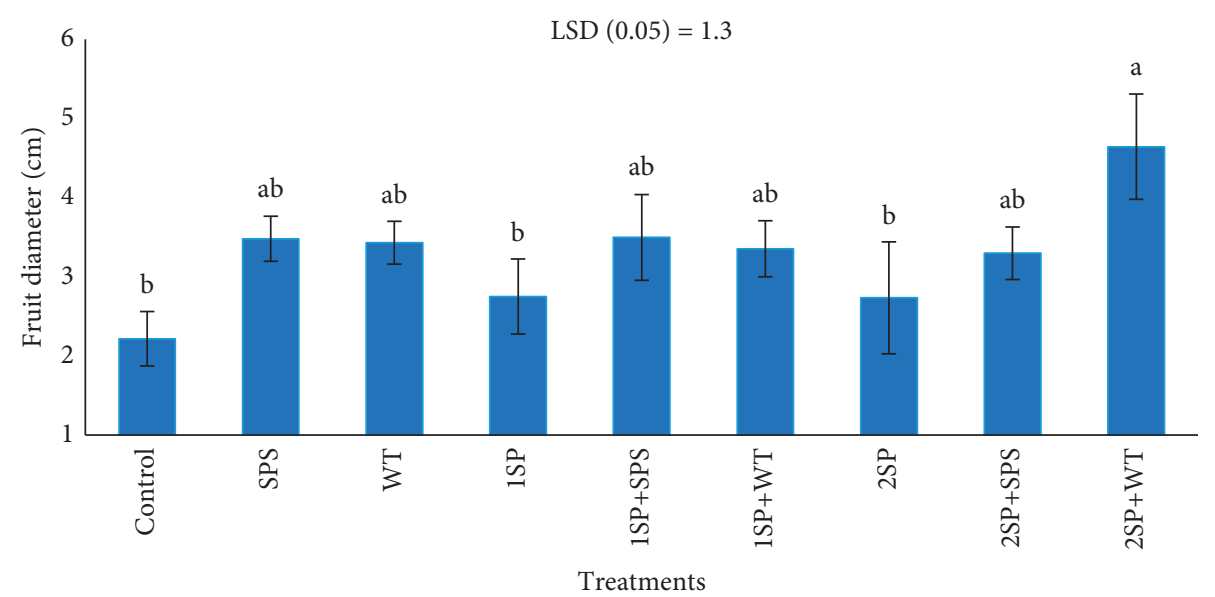

Figure 2: Effect of pruning and staking on fruit diameter. Bars with different letters denote significance at $p<0.05$. Error bars denote the standard error of means. Means comparison was conducted using the least significant difference $(p<0.05)$.

TABLE 1: Marketable fruits weight (kg/ha) of tomato under different pruning and staking methods. Means comparison based on the least significant difference (0.05).

\begin{tabular}{lccc}
\hline Treatments & 8 WAT & 9 WAT & 10 WAT \\
\hline Control & 65 & 145 & 258 \\
SPS & 140 & 253 & 443 \\
WT & 151 & 254 & 519 \\
1SP & 82 & 178 & 258 \\
1SP + SPS & 91 & 251 & 333 \\
1SP + WT & 226 & 291 & 503 \\
2SP & 85 & 256 & 219 \\
2SP + SPS & 161 & 301 & 631 \\
2SP + WT & 369 & 424 & 728 \\
LSD (0.05) & 39.76 & 37.86 & 39.23 \\
CV (\%) & 15.1 & 8.4 & 5.3 \\
\hline
\end{tabular}

LSD, least significant difference (0.05).

The maximum $(7472 \mathrm{~kg} / \mathrm{ha})$ number of nonmarketable fruits recorded on control plots might be attributed to fruits not supported and kept off the floor. This increased disease and rotting of fruits, thereby, increasing nonmarketable fruits. In studies conducted by [23], no pruning plants recorded the maximum nonmarketable fruits. Anonymous [17] reported an increase in fruit yield, a reduction in nonmarketable fruit and enhanced high-quality fruits because of staking. Staking of tomatoes gave higher yield and good quality fruits with higher market value in a study conducted by $[10,11]$ and suggested staking for quality and higher yield of tomato. The current result is also in accordance with [24] who reported increased tomato yield under pruning and staking.

2SP + WT and 1SP + WT increased production cost by $53 \%$ and $57 \%$, respectively, compared to the control plots. This may be attributed to high cost of staking and pruning. The highest and the second highest gross return of $\$ 1010$ and $\$ 771$ per hectare recorded from $2 \mathrm{SP}+\mathrm{WT}$ and $2 \mathrm{SP}+\mathrm{SPS}$, respectively, may be attributed to increased marketable fruits number and weight recorded in these treatments. The highest net return (\$598) per hectare was recorded in $2 \mathrm{SP}+\mathrm{WT}$ and the second highest net return $(\$ 381)$ per hectare. From the economic point of view, 2SP + WT and $2 \mathrm{SP}+$ SPS were more profitable with increased benefit cost ratio of $75 \%$ and $63 \%$, respectively, compared to the control. Lower nonmarketable yield, higher marketable fruits, and higher net return were recorded by Singh [25]. 


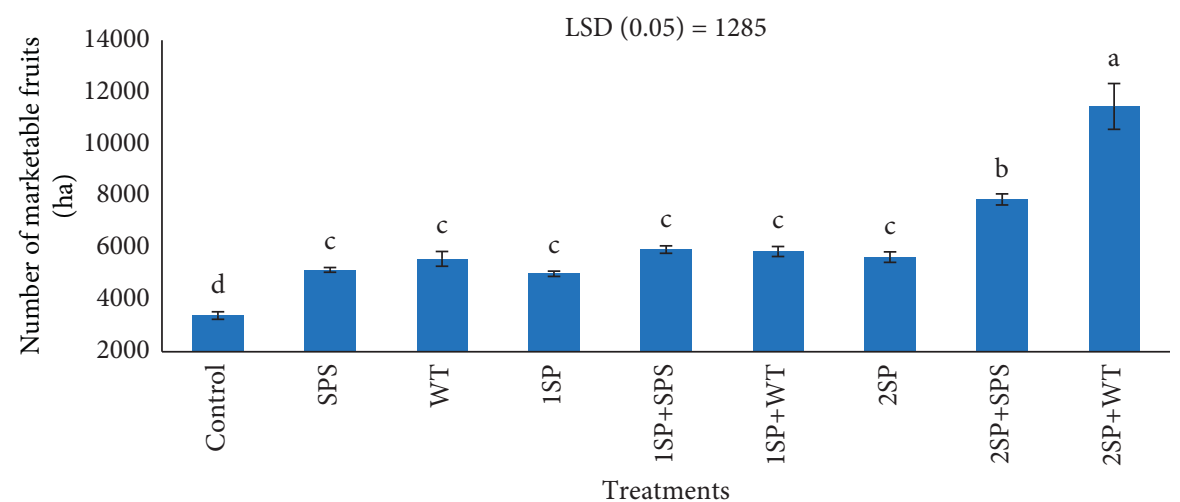

FIGURE 3: Effect of pruning and staking on number of marketable fruits at harvest. Bars with different letters denote significance at $p<0.05$. Error bars denote the standard error of means. Means comparison was conducted using the least significant difference $(p<0.05)$.

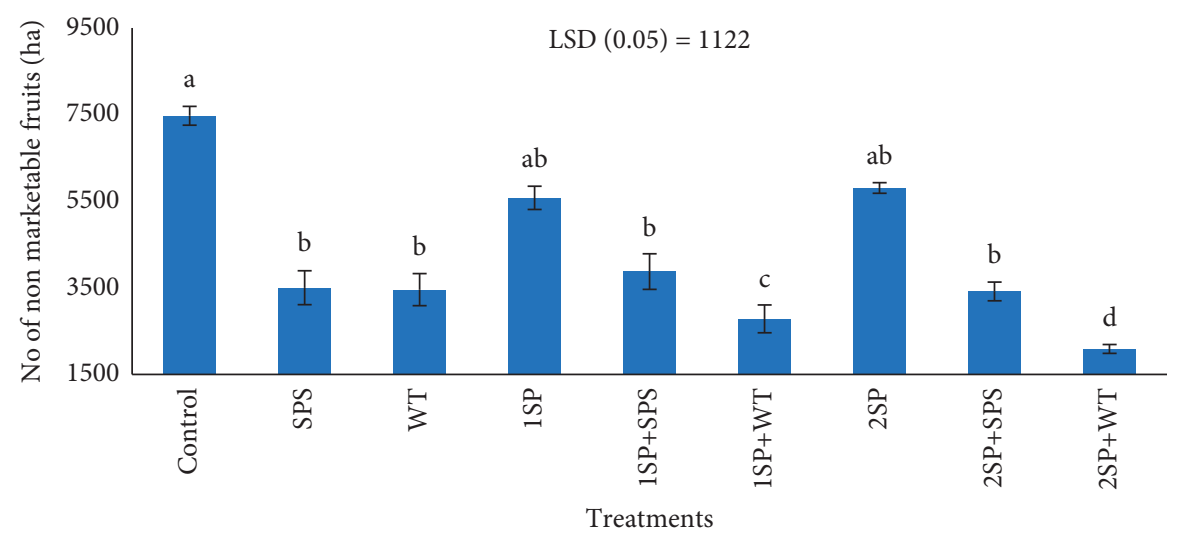

FIgURe 4: Effect of pruning and staking on the number of nonmarketable. Bars with different letters denote significance at $p<0.05$. Error bars denote the standard error of means. Means comparison was conducted using least significant difference $(p<0.05)$.

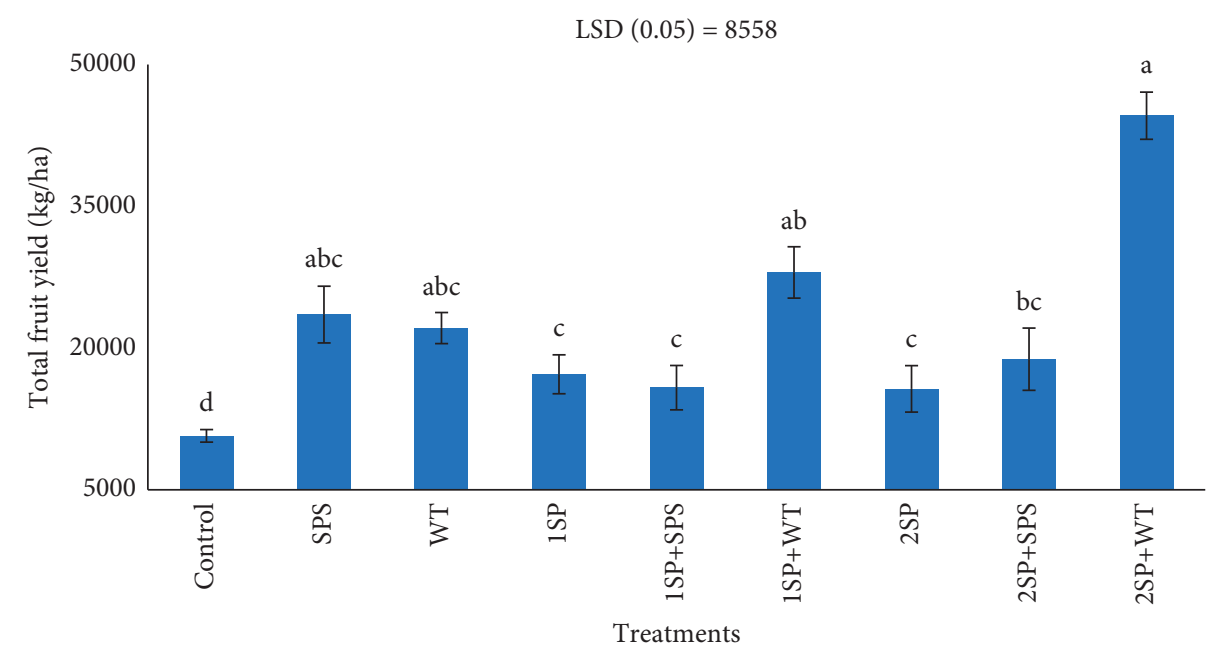

FIGURE 5: Effect of pruning and staking on total fruit yield. Bars with different letters denote significance at $p<0.05$. Error bars denote the standard error of means. Means comparison was conducted using least significant difference $(p<0.05)$. 
TABLE 2: Cost of production, gross return, net return, and benefit/cost ratio of tomato as affected by pruning and staking.

\begin{tabular}{|c|c|c|c|c|}
\hline Treatments & Production cost $(\$ / \mathrm{ha})$ & Gross return $(\$ / \mathrm{ha})$ & Net return $(\$ /$ ha $)$ & $\mathrm{BCR}$ \\
\hline Control & 175.4 & 238.4 & 63.0 & 0.36 \\
\hline SPS & 205.3 & 288.0 & 82.6 & 0.40 \\
\hline WT & 226.7 & 407.1 & 180.4 & 0.80 \\
\hline $1 \mathrm{SP}$ & 180.7 & 321.2 & 140.5 & 0.78 \\
\hline $1 S P+S P S$ & 407.4 & 600.7 & 214.6 & 0.53 \\
\hline $1 \mathrm{SP}+\mathrm{WT}$ & 386.1 & 635.5 & 228.1 & 0.56 \\
\hline 2SP & 184.5 & 360.6 & 176.1 & 0.95 \\
\hline $2 S P+S P S$ & 398.8 & 771.1 & 381.2 & 0.96 \\
\hline $2 \mathrm{SP}+\mathrm{WT}$ & 411.2 & 1010 & 598.3 & 1.46 \\
\hline
\end{tabular}

\section{Conclusion}

Pruning and staking significantly influenced fruit diameter, fruit length, marketable fruits weight, number of marketable fruits, and cost and benefit of tomato production. However, among the different pruning and staking treatments, 2 stem pruning + wire trellising $(2 \mathrm{SP}+\mathrm{WT})$ increased fruit length and diameter, increased marketable fruit weight and number, and net return with a consequential greater cost benefit compared to other treatments. The study has demonstrated that there is hope of sustaining tomato production on highly reduced stakes compared with the current unsustainable staking practice. This would reduce the pressure on the forest to address the problem of deforestation. The two-stem pruning + wire trellising $(2 \mathrm{SP}+\mathrm{WT})$ are recommended for sustainable increased yield and profit.

\section{Data Availability}

The data used to support the findings of this study are included within this article.

\section{Conflicts of Interest}

The authors declare that they have no conflicts of interest.

\section{References}

[1] R. R. Schippers, African Indigenous Vegetables. An Overview of the Cultivated Species, Natural Resources Institute, London, UK, 2000.

[2] GSS (Ghana Statistical Services), Ghana Living Standards Survey (GLSS7), "Poverty Trends in Ghana;" 2005-2017, GSS, Accra, Ghana, 2018.

[3] FAO (Food and Agriculture Organization of the United Nations), FAOSTAT-the Food and Agriculture Organization Corporate Statistical Database Website, FAO, Rome, Italy, 2019, http://www.fao.org/faostat/en/\#home.

[4] J. Z. E. Robinson and S. L. Kolavalli, “"'The case of tomato in Ghana-productivity". Ghana strategy support program (GSSP)," GSSP Working Paper No. 19, 2010.

[5] Ministry of Food and Agriculture (MOFA), "Agriculture in Ghana Facts and Figures (2016)." Statistics, Research, and Information Directorate, MoFA, Accra, Ghana, 2017.

[6] J. Van Asselt, I. Masias, and S. Kolavalli, "Competitiveness of the Ghanaian vegetable sector: findings from a farmer survey," GSSP Working Paper 47, 2018.

[7] Y. S. Gonzalez, Y. Dijkxhoorn, I. Koomen et al., "Vegetable Business Opportunities in Ghana: 2016." The GhanaVeg
Program and Wageningen UR Report, Wageningen UR, Wageningen, The Netherlands, 2016.

[8] U. N. Comtrade, "United nations international trade statistics database," 2019, https://comtrade.un.org/.

[9] J. C. Norman, Tropical Vegetable Crops, Arthur H. Stockwell Ltd, Ilfracombe, England, 1992.

[10] M. O. Akoroda, N. I. Ogbechie-Odiaka, M. L. Adebayo, O. E. Ugwo, and B. Fuwa, "Flowering, pollination and fruiting in fluted pumpkin (Telfairia occidentalis)," Scientia Horticulturae, vol. 43, no. 3-4, pp. 197-206, 1990.

[11] J. G. Amina, B. Derbew, and M. Ali, "Yield and quality of indeterminate tomato (Lycopersicon esculentum mill) varieties with staking methods in jimma, Singapore," Journal of Scientific Research, vol. 2, pp. 33-46, 2012.

[12] S. A. Ennin, N. I. Roland, P. P. Acheampong, M. Numafo, and E. Owusu Danquah, "Mechanization, fertilization and staking options for environmentally sound yam production," African Journal of Agricultural Research, vol. 9, no. 29, pp. 2222-2230, 2014.

[13] J. L. Franco, M. Diaz, F. Dianez, and F. Camacho-Ferre, "Influence of different types of pruning on cherry tomato fruit production and quality," Journal of Food Agriculture and Environment, vol. 7, no. 3 \& 4, pp. 248-253, 2009.

[14] M. Alam, N. Islam, S. Ahmad, M. Hossen, and M. Islam, "Effect of different staking methods and stem pruning on yield and quality of summer tomato," Bangladesh Journal of Agricultural Research, vol. 41, no. 3, pp. 419-432, 2016.

[15] S. Hesamil, S. Khorami, and S. S. Hosseini, "Effect of shoot pruning and flower thinning on quality and quantity of semideterminate tomato (Lycopersicon esculentum Mill.)," Notulae Scientia Biologicae, vol. 4, pp. 2067-3264, 2012.

[16] A. R. Kumar, R. K. Singh, M. Chhillar, and A. Pal, "Influence of fertility levels and support management on tomato (Lycopersicon esculentum Miller) under different planting methods," Crop Research Hisar, vol. 22, no. 3, pp. 437-441, 2001.

[17] Anonymous, “Green Beans Integrated Pest Management." An Ecological Guide Training Resource Text in Crop Development, Major Agronomic Practice, Disease and Insect Ecology, Insect Pest, Natural Enemies and Diseases of Green Bean, Food and Agriculture Organization, Rome, Italy, 2007.

[18] O. Ramirez, W. Loria Martimez, and O. Perez Agruedas, "Pruning systems in tomato cv. Tropic," Bulletein Technico, Universidad de Costa Rica, Facultad Agronomica, vol. 10, no. 6, p. 16, 1977.

[19] N. Ara, M. K. Bashar, S. Begum, and S. S. Kakon, "Effect of spacing and stem pruning on the growth and yield of tomato," International Journal of Sustainable Crop Production, vol. 2, no. 3, pp. 35-39, 2007. 
[20] B. O. Adelaine, "Effects of staking on growth and yield of tomatoes," The East African Agricultural and Forestry Journal, vol. 4, pp. 243-249, 1976.

[21] J. S. Campbell, "Index," East Indians in Trinidad, vol. 38, pp. 257-266, 1961.

[22] O. Salinas, O. Ramirez, and J. Ospina, "Effect of support system, stem pruning and leaf pruning on fruit quality of tomato," Agronomía Colombiana, vol. 11, no. 2, pp. 184-189, 1997.

[23] W. D. Cordt, "Tomato additional stems and pruning pattern determine grading quality and production," Proeftuinnieuws, vol. 9, no. 5, pp. 36-37, 1999.

[24] E. N. K. Sowley and Y. Damba, "Influence of staking and pruning on growth and yield of tomato in the Guinea savannah zone of Ghana," International Journal of Scientific \& Technology Research, vol. 2, 2013.

[25] R. V. Singh, "Performance of kharif tomato as influenced by cultural practices," Indian Journal of Horticulture, vol. 51, no. 2, pp. 192-196, 1994. 